\title{
Case report of aplastic anaemia detected in third trimester of pregnancy: dilemmas faced
}

\author{
Gayathri Dinesh Kamath $^{1 *}$, Sunil Prabhakar Udgire², Divya Katewa ${ }^{1}$
}

\begin{abstract}
${ }^{1}$ Department of Obstetrics and Gynaecology, Fortis Hospital, Bannerghatta, Bangalore, Karnataka, India
${ }^{2}$ Department of Haematology and Bone Marrow Transplantation, Sparsh Hospital Bangalore, Karnataka, India
\end{abstract}

Received: 19 October 2020

Accepted: 03 December 2020

\section{*Correspondence:}

Dr. Gayathri Dinesh Kamath,

E-mail: gayathrimon@gmail.com

Copyright: (c) the author(s), publisher and licensee Medip Academy. This is an open-access article distributed under the terms of the Creative Commons Attribution Non-Commercial License, which permits unrestricted non-commercial use, distribution, and reproduction in any medium, provided the original work is properly cited.

\begin{abstract}
Aplastic anaemia with pregnancy is rarely encountered. Management of aplastic anaemia in pregnancy primarily involves a multidisciplinary approach offering supportive care. Our case was challenging as she developed aplastic anaemia during the third trimester and had refractory thrombocytopenia. She required platelet transfusions on a daily basis for few weeks as well as packed red blood cells frequently. Her leucocyte count was low initially but improved quickly unlike the platelet counts. Initiation of immunosuppressive therapy turned out to be beneficial and culminated in a good outcome. After starting immunosuppressive therapy with eltrombopag and cyclosporine she drifted through term and achieved a normal vaginal delivery.
\end{abstract}

Keywords: Aplastic anaemia, Pregnancy, Eltrombopag

\section{INTRODUCTION}

Aplastic anaemia is a rare disorder. The incidence of aplastic anaemia in Asia is 4-6 per million which is higher compared to about 2 million in Western countries. ${ }^{1}$ It is defined as pancytopenia with a hypocellular bone marrow. Most patients with aplastic anaemia present with anaemia and thrombocytopenia. Causes include exposure to chemicals, drugs and viral infections. Treatment options include bone marrow transplantation, antithymocyte globulin (ATG), cyclosporine A and eltrombopag. Bone marrow transplantation is contraindicated in pregnancy as immunosuppressants are teratogenic to the foetus.

\section{CASE REPORT}

Mrs L, 27 years, second gravida with previous normal delivery came at 29 weeks of pregnancy with history of acute onset headache, fever and cough. Her primary gynaecologist had found pancytopenia and had referred her to our haemato-oncology team at Fortis hospital, Bangalore. At admission, her haemoglobin was $4.2 \mathrm{~g} / \mathrm{dl}$, her total leucocyte count (TLC) was 2.2 thou/ $\mu \mathrm{L}$ (neutrophils 58\%) and platelet count 16 thou/ $\mu$ l.

She was hemodynamically stable, supported with intravenous antibiotics piperacillin and tazobactam combination for her fever, packed red blood cells and platelet transfusions. Her iron profile was normal except for marginal raise in ferritin levels. Her LDH, folic acid, vitamin B 12 levels were normal. ANA profile was normal. Bone marrow aspiration showed hypocellular marrow with decreased megakaryocytes. Bone marrow biopsy was consistent with aplastic anaemia.

Her blood investigations in the first trimester were normal with haemoglobin of $11.6 \mathrm{~g} / \mathrm{dl}$, platelet count 202 thou/ $\mu \mathrm{L}$, TLC of 6.1 thou/ $\mu \mathrm{l}$ (neutrophils $74 \%$ ). Throughout this pregnancy, besides iron and calcium she did not take any medicines and did not give any history of infections. 
Her growth scan at $28^{\text {th }}$ week showed a low-lying placenta with growth corresponding to the gestational age.

A multidisciplinary approach was adopted involving the haematologist, obstetrician, paediatrician, interventional radiologist and a joint counselling was done with the couple. A diagnosis of aplastic anaemia with pregnancy was done and the management plan was discussed with the couple. Bone marrow transplantation with response rates of $70 \%$ was discussed. In view of her ongoing pregnancy, this option could be resorted to only if the pregnancy was terminated due to teratogenic effects of immunosuppressant on the foetus. With a 29-week pregnancy and a low-lying placenta, terminating the pregnancy involved risks with preterm caesarean section and bleeding in view of low platelet count.

With the ongoing pregnancy, the treatment options which were now available as per literature review involved (a) Only cyclosporine alone with a success rate of $20 \%$, (b) Anti-thymocyte globulin (ATG) and cyclosporine with a success rate of $66 \%$, (c) Combination of cyclosporine and ATG and eltrombopag- A thrombopoietin agonist with a success rate of $80 \% .^{2}$ In view of her platelet refractoriness a combination of cyclosporine and eltrombopag was offered. However, there was no data on this combination therapy. The couple chose the latter option and she was discharged from the hospital with a haemoglobin of $8.8 \mathrm{~g} / \mathrm{dl}$, platelet count of 14 thou $/ \mu \mathrm{l}$ and TLC was 5.4 thou/ $\mu$, (neutrophils $75 \%$ ). Her high vaginal swab and urine cultures were negative, antibiotics were stopped.

Treatment was initiated with Cyclosporine $100 \mathrm{mg}$ BD and eltrombopag $150 \mathrm{mg}$ OD. After this, her packed red cells requirements reduced, but she continued to require repeated platelet transfusions. Her liver function tests remained normal. She followed up on outpatient basis with the haematology and obstetric teams and reached $37^{\text {th }}$ week. Her obstetric scan at 37 weeks showed adequate for gestational age foetus with placenta being well away from the OS.

The couple were counselled regarding induction of labour with the involvement of the multidisciplinary team. Her admission blood profile was haemoglobin $7.4 \mathrm{~g} / \mathrm{dl}$, platelet count 28 thou/ $\mu \mathrm{l}$ and TLC was 5.56 thou/ $\mu \mathrm{l}$ (neutrophils 66\%). She received a unit of single donor platelets (SDP) and a unit of packed red blood cells (PRBC) one hour prior to induction of labour and one SDP transfusion three hours later. Labour was induced with Propess (sustained release pessary of dinoprostone). She received intravenous piperacillin and tazobactam for antibiotic prophylaxis and delivered spontaneously a live female baby weighing $2.4 \mathrm{~kg}$. Her induction delivery interval was around 7.5 hours. Her labour and postpartum period remained uneventful with no postpartum haemorrhage or infections. Still, we transfused one unit of SDP and one PRBC post-delivery. She remained afebrile and was discharged in a stable condition with haemoglobin of $8.2 \mathrm{~g} / \mathrm{dl}$, platelet count 21 thou/ $\mu \mathrm{l}$ and total count of 6.2 thou/ $\mu$ l (neutrophils $62 \%$ ). She was advised to continue eltrombopag and cyclosporine. The newborn blood counts on day three were normal. She did not resort to breast feeding as there were not much data on cyclosporine and eltrombopag. The latter was stopped after four months and cyclosporine was eventually tapered to $25 \mathrm{mg}$. Now after 14 months post-delivery she is on cyclosporine $25 \mathrm{mg}$ alternate days and with haemoglobin $10.9 \mathrm{~g} / \mathrm{dl}$, TLC 4.5 thou/ $\mu \mathrm{l}$ and platelet count 135 thou/ $\mu$ l (neutrophils $77 \%$ ).

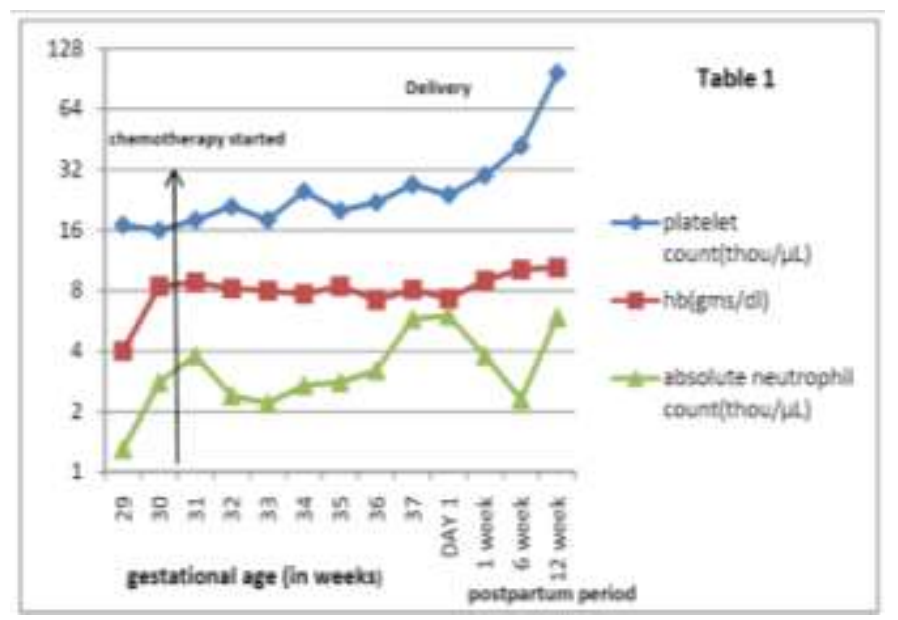

Figure 1: The trend of platelet count, haemoglobin and absolute neutrophil count through the pregnancy.

\section{DISCUSSION}

Aplastic anaemia can first present during pregnancy. Spontaneous remission is observed in some women after pregnancy., ${ }^{3,5}$ An imbalance between placental lactogen, erythropoietin and oestrogen are hypothesised as a cause for aplastic anaemia in pregnancy. The mainstay in the management of pregnancy with aplastic anaemia is supportive care with a multidisciplinary approach involving obstetrician and haematologist. ${ }^{4}$

In our case, the booking blood tests had revealed normal haemoglobin and leucocyte count. Her symptoms of anaemia got the trigger for performing a bone marrow biopsy. Her initial blood picture had all the components of severe aplastic anaemia with low haemoglobin, platelet and leucocyte count. Her leucocyte count improved within a week. Literature review suggests that neutrophil counts increase during normal pregnancy and that thrombocytopenia is one of the risk factors for complications in pregnancy with aplastic anaemia. ${ }^{5}$ Platelet transfusions were given daily as her counts hovered around 14, thou/ $\mu \mathrm{l}$ (Figure 1). The platelet refractoriness and the high risk of alloimmunisation made it difficult to manage initially. At this stage, she was around 30 weeks, and in the mother's interest, even if we had considered delivering her with severe aplastic 
anaemia, it would not have been prudent with a placenta lurking close to the internal OS.

Table 1: Protocol of management of aplastic anaemia during labour

\section{Preparation}

- MDT involving anaesthesiologist, gynaecologist, haematologist, blood banking charge, intensivist, intervention radiologist, neonatologist.

- Arrangement of donors for platelet and PRBC

- Adequate blood stock in blood bank

- Arrangement of Novo 7 vials in pharmacy.

- Arrange isolation bed in MICU.

Role of anaesthetist

- No lumbar puncture/neuraxial technique for anaesthesia oranalgesia. ${ }^{8}$

- No NSAIDS for pain control. Opioids, Nitric oxide acceptable. $^{8}$

\section{Patient preparation}

- Type of delivery: vaginal preferable. ${ }^{2}$

- Blood thresholds: platelet count $>20000$ for vaginal delivery, >50000 for LSCS. HB >8 GM/DL, If absolute neutrophil count is 5000 Prophylactic GCSF. ${ }^{8}$

- $\quad$ Start prophy lactic antibiotic Inj. Piptaz 4.5 gm 6 hours before induction/pre-op. (As per our hospital protocol).

- Pre-op/ before induction:1 SDP transfusion/6 RDP transfusion 1-2 hour before.

- Intra OP 1SDP/6RDP transfusion. 1-unit PRBC transfusion.

- If bleeding continues factor VII (Novo 7) $90 \mathrm{mcg} / \mathrm{kg}$ slow IV push over 2-5 min. ${ }^{9}$

- Repeat dose of Novo 7 after 6 hours if haemostasis is not achieved. ${ }^{9}$

- Post op/post-delivery 1 SDP/ 6 RDP transfusion.

- Monitor platelet 12 hourly, transfuse 6 units RDP/1unit -SDP to maintain platelet count $>20000$ for 5 days post $\mathrm{OP}{ }^{8}$

- Treat fever aggressively as per febrile neutropenia protocol.

Supportive care is the mainstay of treatment in aplastic anaemia with pregnancy. The protocol we followed is as given in Table 2. Aim to maintain the platelet count over 20 thou/ $\mu \mathrm{l}$ and haemoglobin over $8 \mathrm{gm} / \mathrm{dl}$. Definitive treatment with eltrombopag and cyclosporine combination helped our patient to continue till 37 weeks when her placenta migrated onto the upper segment. Eltrombopag is a peptide, oral thrombopoietin receptor agonist. There is no data on its safety in aplastic anaemia with pregnancy. However, it has been tried in the treatment of pregnant women with refractory ITP in the third trimester. ${ }^{6}$ Cyclosporin is safe during pregnancy. ${ }^{4}$ Anti-thymocyte globulin, an immunosuppressant has been tried in pregnant women however with limited data.
Induction of labour was planned for logistic reasons to maintain a good platelet count and haemoglobin. As her leucocyte counts were normalised, induction of labour with vaginal insertion with Propess was considered to be safe. Propess is a sustained release vaginal delivery system of dinoprostone $10 \mathrm{mg}$.

Considering her platelet count and haemoglobin improved after delivery, pregnancy may have been a triggering event.

\section{CONCLUSION}

A team approach and robust support from the family played a key role in successfully managing our case. The leucocyte count recovered early and hence infections did not pose a threat. This patient seemed to be very refractory to platelet transfusion and needed several platelet transfusions initially.

Eltrombopag probably is a wonder drug to improve outcome in pregnancy with aplastic anaemia but safety in pregnancy needs to be ascertained.

Funding: No funding sources

Conflict of interest: None declared

Ethical approval: Not required

\section{REFERENCES}

1. Aitchison RG, Marsh JC, Hows JM, Gordon RNH, Smith EC. Pregnancy associated aplastic anaemia: A report of five cases and review of current Management. Bri J Haematol. 1989;73:541-5.

2. Townsley DM, Scheinberg P, Winkler T. Eltrombopag Added to Standard Immunosuppression for Aplastic Anemia. N Eng J Med. 2017;376:154050 .

3. Choudry VP, Gupta S, Gupta M, Kashyap. Pregnancy associated aplastic anaemia- a series of 10 cases with review of literature. Haematol. 2002:7:233-8.

4. Guidelines for the diagnosis and management of Adult Aplastic anemia. Bri J Haematology. 2016;172:187-207.

5. Tichelli A, Socie G, Marsh J, Barge R, Frickhofen N, McCann S. et al Outcome of pregnancy and disease course among women with aplastic anaemia treated with immunosuppression. Ann Intern Med. 2002;137:164-72.

6. Purushotahman J, Puthumana KJ, Kumar A, Innah SJ, Gilvaz S. A case of refractory immune thrombocytopenia in pregnancy managed with Eltrombopag. Asian J Tranfus Sci. 2016;10:155-8.

7. McKay DB, Josephson MA. Pregnancy in recipients of solid organs-effects on mother and child. N Eng J Med. 2006;354:1281-93.

8. Al Hammadi AM, Sallah S. Efficacy and safety of recombinant factor VIIa in the treatment of bleeding 
episode in patients with aplastic anaemia. J Thromb Haemost. 2007;5:435-6.

9. Riveros-Perez E, Hermesch AC, Barbour LA, Hawkins JL. Aplastic anaemia during pregnancy: a review of obstetric and anesthetic. Inte J Women's Health. 2018:10:117-25.
Cite this article as: Kamath GD, Udgire SP, Katewa D. Case report of aplastic anaemia detected in third trimester of pregnancy: dilemmas faced. Int J Reprod Contracept Obstet Gynecol 2021;10:381-4. 